\title{
ESTÁGIO CURRICULAR SUPERVISIONADO: A FORMAÇÃO DO PROFESSOR-COLABORADOR
}

\begin{abstract}
Larissa Cerignoni Benites
Universidade Estadual de São Paulo

Marina Cyrino

Universidade Estadual de São Paulo

Samuel de Souza Neto

Universidade Estadual de São Paulo
\end{abstract}

\begin{abstract}
Resumo
O presente artigo apresenta dois programas de formação para professores das escolas (professores-colaboradores) que recebem estagiários dos cursos de Licenciatura em Educação Física e Pedagogia da Universidade Estadual Paulista - Rio Claro. Com isso, objetivamos: (a) apresentar duas propostas de formação para professorescolaboradores situadas na Unesp - Rio Claro para os cursos de Pedagogia e Educação Física e (b) averiguar como os professores participantes se posicionam frente ao estágio após terem seguido uma formação. Com uma metodologia de natureza qualitativa, realizamos entrevistas semi-estruturadas e observações dos professores-colaboradores e sua relação com os estagiários no momento do estágio. Como resultados, os professores apontam a importância dos cursos de formação como uma preparação para receber estagiários, bem como uma oportunidade de troca com os colegas. Veem sua função como orientadores, passando suas experiências para os estagiários. Concluiu-se que ambas as propostas, em desenvolvimento, contribuem para que os professores se percebam como formadores.
\end{abstract}

Palavras-Chave: Estágio Supervisionado; Formação de Professores; ProfessorColaborador.

Olh@ res, Guarulhos, v. 1, n1, p. 116-140, maio. 2013. 


\title{
CURRICULAR INTERNSHIP: THE MENTOR'S EDUCATION
}

\begin{abstract}
The research discuss about internship in Physical Education and Pedagogy undergraduate at São Paulo State University - campus Rio Claro, specifically about two mentors' education proposals, school teachers that receive trainees of this courses. This paper aims (a) to present two mentor's education proposals at São Paulo State University - campus Rio Claro, to Pedagogy and Physical Education undergraduate and (b) to examine how the mentors take a stand on themselves in face to internship after experiencing an education. This is a qualitative research, that was involved semistructured interview and observations with the mentors and theirs relationship with trainees in internship moment. As results, the mentors noted the education courses importance as a preparation to receive trainees, and a experiences return with their peers. About their role, they noted like that guide, passing their experiences to trainees. Concluded that both of proposals contribute to mentors cognize themselves as teachers educators.
\end{abstract}

Keywords: Internship; Teacher Education; Mentors.

Olh@ res, Guarulhos, v. 1, n1, p. 116-140, maio. 2013. 


\section{Introdução}

No Brasil, a temática Estágio Curricular Supervisionado, anteriormente chamada de Prática de Ensino, apresenta vestígios sobre o seu desenvolvimento em diferentes períodos históricos. Contudo é a partir de 1939 (BRASIL, 1939), com a criação do curso de Didática, que se começou a explorar as discussões sobre o assunto. Do ponto de vista dos normativos para os cursos de licenciatura, há uma série de implementações vinculadas à questão do estágio supervisionado no âmbito de uma política pública de formação de professores, podendo-se citar a Resolução CFE 9 de 1969, introduzindo a ideia de "prática de ensino", estágio supervisionado, ou seja, uma prática de ensino supervisionada (BRASIL, 1969); a LDB 9394 de 1996 que fixou a carga horária da "prática de ensino" em 300 horas, compreendendo-a como disciplina de conhecimento e como atividade de estágio (BRASIL, 1996) e a Resolução CNE 1 de 2002 que assumiu a perspectiva de estágio curricular supervisionado com 400 horas (BRASIL, 2002). Em todas estas orientações fica claro que há um professor supervisor da universidade que acompanha este processo sem mencionar de forma explicita o perfil e o papel do professor da escola que acompanha ou recebe este estagiário.

Neste percurso, a medida mais recente foi a Lei $\mathrm{n}^{\circ} 11.788$ de 2008 (BRASIL, 2008), desvinculada da política de formação de professores, inaugurando um novo procedimento nas políticas públicas de formação profissional. A nova lei normatizou os estágios, de um modo geral (sem diferença entre os espaços, nesse estudo a parte concedente foi considerada a escola), colocando diretrizes para as partes cedente (universidade) e concedente (outro espaço) na forma de um contrato institucional. O professor da universidade vinculado ao estágio supervisionado recebeu a denominação de orientador, enquanto que a pessoa designada para acompanhar o estagiário recebeu o nome de supervisor.

Há avanços no que diz respeito às prescrições relativas à instituição formadora, instituição do estágio, ao próprio estudante, criando um melhor delineamento

Olh@ res, Guarulhos, v. 1, n1, p. 116-140, maio. 2013. 
do amparo legal, mas deixa em aberto a preocupação com a formação daquele que recebe o estagiário na parte concedente (no nosso caso o professorcolaborador da escola), assim como da necessidade das instituições oferecerem modalidades de aperfeiçoamento para estes profissionais considerados parceiros no processo de estágio (BRASIL, 2001).

Nesse contexto, Souza Neto et al (2012) ao analisarem a realidade brasileira do estágio supervisionado assinalaram que o professor da escola é formado para ensinar e não para ser um formador. Neira (2012, p.198), por sua vez, ao ler os dados de um relatório de estágio do curso de Formação de Professores de Educação Física da USP apontou que os estudantes "se queixam da falta de uma participação mais ativa dos professores das escolas", da necessidade de “integração entre os envolvidos no processo de estágio". Nesta direção também se aponta para a importância de se investigar a formação do professorcolaborador (GERVAIS, 2010; PORTELANCE et al. 2008; BORGES, 2011) envolvendo a dinâmica acadêmica e escolar. Fato este que é apoiado por Borges (2008) ao colocar que estabelecer parcerias entre as instituições universitárias e as escolas é de suma importância para o desenvolvimento do estágio, bem como para a formação do professor-colaborador.

Porém, em se tratando de Brasil há uma grande variedade de perspectivas para se trabalhar com estágio na formação de professores, visando levar o estudante a se constituir um professor. Entre as estratégias estão: micro-ensino, plano real, portfólio, narrativas, relato de experiência etc., opções que colocam a sua ênfase na figura do estagiário. Todavia, não existe uma política nacional para a formação do professor-colaborador apesar das diferentes iniciativas locais que tentam suprir necessidades vinculadas ao processo de estágio. Da mesma forma, podemos citar os estudos sobre a tutoria apontados por Cerri (2002), Rosa et al. (2003) e Terrazan (2000) relacionados à formação de professores em cursos de licenciatura como Pedagogia, Ciências e Física, trazendo como benefícios o senso de coletividade da "classe de professores", a aprendizagem da docência e os atributos do fazer docente.

Olh@ res, Guarulhos, v. 1, n1, p. 116-140, maio. 2013. 
Outra perspectiva aparece na Universidade Federal de São Paulo que criou um Programa de Residência Pedagógica para o curso de Pedagogia, estabelecendo um vínculo entre formação inicial e continuada por meio da imersão dos residentes (estagiários) em vivências sistemáticas e temporárias nas práticas pedagógicas de docentes e gestores escolares profissionais, acompanhadas pela orientação de um preceptor - docente da universidade - e de professores e gestores das escolas-campo, considerados como colaboradores no processo de formação inicial. Os principais desafios foram a questão da adequação do curso com a escola, o embate com o discurso recorrente de incompreensão dos professores e a revisão do modelo de aprendizagem na formação inicial (GIGLIO, 2010).

Na Universidade de São Paulo, campus Ribeirão Preto, para o curso de Pedagogia, vem se implementando uma proposta de acompanhamento de estágios curriculares. Desde 2009, existe a presença de um "técnico" que deve ter como formação mínima o ensino superior, com licenciatura, denominado "Educador" que auxilia na ligação entre a universidade e escola, fazendo a ponte entre as duas instâncias e que acaba se tornando, indiretamente, um agente de formação (CORREA, 2009), porém a formação do professorcolaborador continua em aberto.

Dessa forma, o presente trabalho teve como objetivos: (a) apresentar duas propostas de formação para professores-colaboradores situadas na Universidade Estadual Paulista, Campus Rio Claro para os cursos de Licenciatura em Pedagogia e em Educação Física e (b) averiguar como os professores participantes se posicionam frente ao estágio após terem seguido esta formação.

\section{Percursos Metodológicos}

$\mathrm{Na}$ busca desses dados optou-se pela pesquisa qualitativa, tendo como paradigma o construtivismo social e como técnicas: fonte documental, observação, entrevista semi-estruturada e análise de conteúdo. A pesquisa qua

Olh@ res, Guarulhos, v. 1, n1, p. 116-140, maio. 2013. 
litativa "consiste em um conjunto de práticas materiais e interpretativas que dão visibilidade ao mundo", além de envolver a "coleta de uma variedade de materiais empíricos (...) que descrevem momentos e significados rotineiros e problemáticos na vida dos indivíduos” (DENZIN \& LINCOLN, 2006, p.17). Nesta direção, Alves-Mazzotti e Gewandsznadjer (1998, p. 133) compreendem que o paradigma do construtivismo social "enfatiza a intencionalidade dos atos humanos e o 'mundo vivido' pelos sujeitos, privilegiando as percepções dos atores".

Nesse estudo os participantes foram: cinco professores-colaboradores vinculados ao programa de estágio do curso de Licenciatura em Educação Física e seis professoras-colaboradoras vinculadas ao programa de estágio do curso de Licenciatura em Pedagogia, todavia cabe dizer que o número de professores participantes dos cursos oferecidos foi maior e para este estudo escolhemos uma amostra.

Como fonte documental compreendemos, assim como Lüdke e André (1986, p.39), "uma fonte 'natural' de informação", não se tratando apenas de informações contextualizadas, mas também as quais fornecem dados sobre um contexto do qual surgem. Aqui, utilizamos como fonte documental a proposta dos cursos de formação. Outra técnica utilizada foi a observação, que teve como intuito "identificar e descrever diversos tipos de interações e processos humanos" (VIANNA, 2007, p.12). Nesse sentido, as observações foram realizadas nas escolas em que os professores-colaboradores atuavam. $\mathrm{Na}$ Educação Física, os participantes foram observados durante 2 meses e cada um teve por volta de 34 horas de observação e os dados foram registrados num diário de campo; enquanto que na Pedagogia a observação dos participantes contemplou 3 meses, sendo que para cada docente totalizaram em média 26 horas.

Utilizou-se, ainda, a entrevista semi-estruturada que "se desenrola a partir de um esquema básico, porém não aplicado rigidamente, permitindo que o entrevistador faça as necessárias adaptações” (LUDKE \& ANDRÉ, 1986, p.34).

Olh@ res, Guarulhos, v. 1, n1, p. 116-140, maio. 2013. 
As entrevistas foram marcadas de acordo com a possibilidade do participante, em local e horário escolhido por ele. As mesmas foram transcritas e tabuladas.

Os professores participantes do estudo foram nomeados de PC (ProfessoresColaboradores) e numerados de 1 a 11 . O grupo de professores vinculado à Educação Física (PC1 a PC5) possuíam formação em nível superior, estando envolvidos com o ensino há pelo menos 10 anos. Recebiam estagiários há no mínimo cinco anos, participando da parceria com a Universidade há três anos. Deste grupo três são mulheres e dois homens trabalhavam em unidades escolares distintas e em diferentes níveis de educação. Estes professores assinaram o termo de consentimento livre e esclarecido aprovado pelo comitê de ética da instituição (Parecer 1422 de 02 de março de 2009).

O grupo da Pedagogia (PC6 a PC11) foi composto por seis mulheres, sendo três professoras em início de carreira com no máximo quatro anos de experiência e três entre 10 e 23 anos de trabalho como docente. Com relação à formação destas participantes, cinco tem nível superior em Pedagogia, sendo que destas, três também tem o curso Magistério como formação inicial. Vale destacar que apenas uma professora estava em formação no curso de Pedagogia, entretanto ela tinha o Magistério como formação anterior. Das seis docentes, três participavam da parceria há pelo menos dois anos e uma pela primeira vez que recebia estagiários. Todas as professoras atuavam na rede municipal de ensino da cidade, nas séries iniciais do Ensino Fundamental. Estas professoras assinaram o termo de consentimento livre e esclarecido aprovado pelo comitê de ética da instituição (Parecer 0931 de 13 de março de 2010).

Quadro 1- Caracterização dos participantes do estudo

\begin{tabular}{|c|c|c|c|c|}
\hline $\begin{array}{c}\text { Professor- } \\
\text { Colaborador }\end{array}$ & Gênero & Formação & $\begin{array}{c}\text { Tempo de } \\
\text { carreira } \\
\text { (anos) }\end{array}$ & Nível em que atua \\
\hline PC1 & Feminino & Licenciatura em Educação Física & 35 & Educação infantil e Ensino Fundamental \\
\hline PC2 & Masculino & Licenciatura em Educação Física & 25 & Ensino Médio \\
\hline PC3 & Feminino & Licenciatura em Educação Física & 27 & Educação infantil e Ensino Fundamental \\
\hline PC4 & Feminino & Licenciatura em Educação Física & 13 & Ensino Fundamental \\
\hline PC5 & Masculino & Licenciatura em Educação Física & 9 & Educação infantil e Ensino Médio \\
\hline PC6 & Feminino & Magistério/cursando Pedagogia & 10 & $3^{\mathbf{0}}$ ano- Ensino Fundamental \\
\hline PC7 & Feminino & Pedagogia & 3 & $3^{\mathbf{0}}$ ano- Ensino Fundamental \\
\hline
\end{tabular}

Olh@ res, Guarulhos, v. 1, n1, p. 116-140, maio. 2013. 


\begin{tabular}{|c|c|c|c|c|}
\hline PC8 & Feminino & Pedagogia & 2 & $3^{\mathbf{o}}$ ano- Ensino Fundamental \\
\hline PC9 & Feminino & Pedagogia & 4 & $1^{\mathbf{o}}$ ano- Ensino Fundamental \\
\hline PC10 & Feminino & Magistério/Pedagogia & 20 & $1^{\mathbf{o}}$ ano- Ensino Fundamental \\
\hline PC11 & Feminino & Magistério/Pedagogia & 23 & $4^{\mathbf{o}}$ ano- Ensino Fundamental \\
\hline
\end{tabular}

A partir dos dados encontrados utilizou-se como técnica a análise de conteúdo proposta por Bardin (1979). Este prevê uma análise das comunicações, utilizando procedimentos sistemáticos e objetivos para a descrição do conteúdo das mensagens. Com o cruzamento das várias fontes chegou-se a criação de temáticas (a proposta do curso, o perfil dos professores-colaboradores, a forma de orientação empregada durante o estágio, a concepção do estágio, a relação entre estagiários e professores-colaboradores, entre outros).

\section{As propostas de formação de Professores-Colaboradores}

O professor-colaborador é aquele que recebe estagiário em situação oficial de estágio, entretanto antes de tudo, ele é um professor. Alguém que foi forjado pela sua constituição profissional e que agrega saberes, competências e experiências relacionadas a um universo profissional e pessoal.

A figura do professor-colaborador é de alguém que congrega de maneira mesclada uma formação para ensinar e após um determinado tempo de carreira, passou a participar da formação de futuros professores. Porém, na grande maioria das vezes esse último indício é pouco explorado, podendo-se colocar ou constatar que o professor-colaborador se assemelha a um artesão que aprendeu o seu trabalho pelo fazer e ensina pela mesma dinâmica, como na proposta da Escola de Ofício (RUGIU, 1998), onde o mestre passa (transmite) seus ensinamentos para o discípulo. Contudo, esses professores da escola são considerados atores imprescindíveis para a orientação e relação com os estagiários. Não distante desta realidade, a Universidade Estadual Paulista, Campus Rio Claro - UNESP/RC, vem desenvolvendo iniciativas de formação para estes professores considerados parceiros no momento do estágio curricular supervisionado.

Olh@ res, Guarulhos, v. 1, n1, p. 116-140, maio. 2013. 


\section{Professores Parceiros: o estágio no curso de Pedagogia}

A proposta de formação para professores-colaboradores, presente no curso de Licenciatura em Pedagogia foi idealizada por Sarti (2009) na proposta do projeto "Parceria Intergeracional e Formação Docente" vinculado à rede municipal de ensino, tendo como objetivo aproximar os professores da escola dos estagiários de maneira que pudessem trocar experiências. Estes professores, nomeados de professores parceiros, deveriam desenvolver um projeto pedagógico em parceira com os estagiários, sendo convidados a participar de um curso de extensão oferecido pela professora supervisora (professora universitária que supervisiona os estágios). Partindo das experiências do estágio, os parceiros partilhariam as impressões, saberes, dúvidas, entre outros, na perspectiva de se estabelecer um vínculo mais próximo e tornar o momento do estágio mais valorativo, sendo uma dinâmica que deveria aproximar mais a universidade do professor e vice-versa. Para Sarti (2009, p.134), “os professores em exercício são chamados a desempenhar o papel de iniciadores de uma nova geração docente, algo que lhes possibilita vivenciar novas aprendizagens, ao mesmo tempo que sentimentos de valorização de seus saberes e práticas profissionais".

Cabe ressaltar que nesta proposta os professores da escola não eram considerados tutores, não tinham "responsabilidades institucionais comumente associadas a este papel" (SARTI, 2009, p. 136), mas assumiam a postura de parceiros na aprendizagem da docência. Destaca-se que os professores das escolas eram convidados a receber estagiários, não havendo nenhuma seleção para tal procedimento. Assim, no ano de 2011, a Secretaria Municipal de Educação propôs fechar uma parceria com algumas escolas para que o acompanhamento da supervisora ficasse mais centralizado. Neste ano, o curso de 60 horas contou com a presença de 31 professores (PC) e um membro da Secretaria Municipal de Educação responsável pela área do Ensino Fundamental I e estágios vinculados à rede municipal de educação. A progra-

Olh@ res, Guarulhos, v. 1, n1, p. 116-140, maio. 2013. 
mação seguiu a perspectiva de leituras no inicio do curso e posteriormente focou-se na troca de experiências entre os docentes.

Porém, em anos anteriores não teve o mesmo número de professores envolvidos. No estudo de Cyrino et al. (2012) sobre o trabalho desenvolvido na UNESP foi assinalado que em 2008, somente oito professores fizeram o curso, já em 2011 este número cresceu visivelmente, acrescentando que três professores entenderam o estágio como um espaço de aprendizado do futuro docente.

Esta compreensão é referendada por Pimenta e Lima (2004) quando assinalam que o estagio deve aproximar o aluno da realidade na qual irá atuar, podendo ser visto também como um lugar de reflexão sobre a construção e fortalecimento da identidade docente. Cochran-Smith (1991 apud GARCIA, 1999, p.100) vai afirmar também que se forma "uma cultura de colaboração entre os membros de ambas as instituições, através da realização de projetos conjuntos, onde os professores em formação possam, ocasionalmente, participar".

\section{Educação Física: A formação dos Professores-Colaboradores}

No caso da Licenciatura em Educação Física se registra a iniciativa de Souza Neto e Benites (2008) em curso de extensão de 60 horas para professorescolaboradores e outros professores de Educação Física, num total de 30 docentes vinculados a Secretaria Municipal de Educação de Rio Claro, com o intuito de discutir, refletir e repensar aspectos da formação, como saberes, prática pedagógica e o entendimento sobre o professor, bem como sobre a corresponsabilidade pela formação de futuros professores, evidenciando o processo de colaboração no estágio. Entre os objetivos constaram (a) estabelecer um momento de formação e troca de experiências para os professores de Educação Física; (b) evidenciar a compreensão a respeito do

Olh@ res, Guarulhos, v. 1, n1, p. 116-140, maio. 2013. 
entendimento de quem é o professor e qual é o seu papel, prática pedagógica, profissão e estágio; (c) dar suporte para o professor que é corresponsável pela formação de futuros professores e (d) enfocar a questão do compromisso e responsabilidade para com o ensino de Educação Física no momento do estágio.

A proposta do curso teve como foco a temática da formação de professores voltada para o conhecimento profissional do professor e para a aprendizagem da docência, principalmente no entendimento de uma epistemologia da prática e ao abrir flancos para tipos alternativos de investigação até então não ousadas, considerando paradigmas vigentes e a preocupação com o modelo processoproduto (MIZUKAMI et al., 2002). O conteúdo das leituras recaiu-se sobre o processo de formação de professores (NÓVOA, 1992), profissionalização do magistério (LUDKE; BOING, 2004), reflexão sobre a prática pedagógica (SCHÖN, 1992; ORTIZ, 2003), saberes docentes (TARDIF, 2002; BORGES, 2008), valorização das experiências docentes (CONTRERAS, 2002; BONDÍA, 2002), entre outros. As estratégias de trabalho consideraram leitura de textos, apresentação de trabalhos e cumprimento de um estágio de 32 horas, podendo envolver: (a) exercícios de observação sistemática da prática-pedagógica; (b) preparação de mini-programas de capacitação e (c) acompanhamento dos estágios dos estudantes do curso de Licenciatura em Educação Física da UNESP-RC.

A partir desse curso e iniciativas anteriores no ano de 2009 manteve-se o vínculo com encontros para discussão de temáticas específicas e de maneira mais isolada com um pequeno grupo que não ultrapassava a 10 docentes; no ano de 2010 se fortaleceu a perspectiva da parceria com estas pessoas, tendo no primeiro semestre, encontros para acompanhar as novas demandas da Secretaria e no segundo semestre a apresentação de um novo curso de extensão " $O s$ desafios da prática como lócus central da formação docente em educação fisica”, enquanto que ano de 2011 houve encontros na universidade com os professores-colaboradores que receberam estagiários.

Olh@ res, Guarulhos, v. 1, n1, p. 116-140, maio. 2013. 
Sobre o trabalho desenvolvido nos estágios supervisionados em Educação Física da UNESP de Rio Claro, Souza Neto et al. (2012, p.10) colocou que os cinco professores-colaboradores participantes "foram unânimes em dizer que não há um espaço formal para se aprofundar as trocas didáticas ou de colaboração, permanecendo uma espécie de buraco negro entre estes dois espaços formativos". Concluindo...

Os professores-colaboradores percebem o espaço do estágio como um lugar de aprendizagem, mas não compreendem de maneira clara qual é o seu papel e função durante a ocorrência do mesmo. No diálogo entre supervisor, professores e estagiários emerge a constatação da colaboração como uma estrada de mão dupla (SOUZA NETO et al., 2012, p. 10).

Assim, concordamos com Mizukami et al. (2002) quando afirma que os trabalhos colaborativos entre universidade e escola tem alterado as representações e as práticas nas escolas, bem como poderíamos incluir, as práticas de ensino na universidade.

\section{Caminhos para a formação de colaboradores}

As propostas de formação apresentadas foram iniciativas locais que se constituíram como possibilidades de formação para os professorescolaboradores. Embora estando na mesma universidade e seguindo os princípios da instituição no que diz respeito às dinâmicas do estágio, cada curso retratou os colaboradores com as suas especificidades, por se entender que embora todos sejam professores cada área apresenta um perfil particular, pedagogos e professores de Educação Física.

Ambas as propostas contemplaram como eixo básico a questão da valorização da prática e da experiência, pois a formação partiu da prática. Por meio dos relatos e das experiências é que os professores-colaboradores começaram a perceber que o seu papel é importante e existe a necessidade de se ter uma formação mais densa. Outro ponto comum é a questão da prática reflexiva, pois as propostas apresentam como possibilidade a noção de se refletir sobre a

Olh@ res, Guarulhos, v. 1, n1, p. 116-140, maio. 2013. 
própria prática e a partir disso refletir sobre a prática dos estagiários analisando seus limites e avanços, sendo capaz de fornecer feedbacks.

Contudo trata-se de iniciativas isoladas que estão sujeitas as decorrências políticas (como a troca de prefeitura de tempos em tempos) e, sobretudo da compreensão de gestores da escola sobre estágio para que se estabeleça uma parceria. Tardif (2000, p.12) nos lembra de que o objeto do trabalho docente são seres humanos e, por conseguinte, os saberes dos professores carregam as marcas do ser humano. Desse modo, as pessoas que trabalham com seres humanos devem "habitualmente contar consigo mesmas, com seus recursos e com suas capacidades pessoais, com sua própria experiência e com a de sua categoria".

\section{As ponderações dos professores-colaboradores}

A partir do contexto do curso, dados da observação e da entrevista foram organizados em quatro pontos de reflexão-resultado. $\mathrm{O}$ primeiro diz respeito a quem são os professores que participam deste processo de formação, o segundo é como agem durante o período de estágio em relação ao estagiário, o terceiro refere-se a qual é o seu papel e por fim, o quarto, como se dá a relação com a universidade.

\section{Como os professores-colaboradores agem durante o processo de estágio?}

Os professores-colaboradores que recebem estagiários da Educação Física quando interrogados e observados sobre suas ações durante o momento do estágio vão sublinhar que estabelecem relações harmoniosas, porque são receptivos, abrem as portas da escola para que aconteçam os estágios, mostram como funciona a rotina da escola, conversam sobre os conteúdos específicos da disciplina, integram os estagiários nas atividades escolares, como reuniões pedagógicas e sala de professores: "eu acho que estou ajudando um pouco eles

Olh@ res, Guarulhos, v. 1, n1, p. 116-140, maio. 2013. 
a melhorarem a relação deles aqui na escola com os alunos e pra eles perceberem como é realmente a escola, como é o dia-a-dia” (PC4).

Com relação à postura, eles se colocam a disposição dos estagiários para eventuais perguntas, para auxiliá-los caso haja algum problema decorrente da sala de aula e estão sempre presentes durante as aulas dos estagiários. Este ponto merece atenção porque, no Brasil, os professores que colaboraram no estágio possuem uma representação de serem frequentemente ausentes do momento do estágio para executar outras tarefas enquanto o estagiário "toma conta" dos alunos e das aulas.

No meu estágio a gente chegava, tanto na observação quanto na prática, a gente chegava e muitas às vezes ou quase todas as vezes o professor falava: está aqui o material! Nem falava o que tinha proposto para ser trabalhado e acabava deixando sob nossa responsabilidade a aula. Então a gente tinha que aprender na marra (...) agora eu, como professor, não consigo ficar muito alheio (PC5).

Com relação à interferência nas aulas, tanto as professoras da Pedagogia quanto os professores da Educação Física interferem nas atividades desenvolvidas pelos estagiários quando há comportamentos perturbadores por parte dos alunos que impossibilitam a ação dos estagiários e eles interveem para que se mantenha o controle da classe.

$\mathrm{Na}$ Pedagogia as professoras procuram sempre alertar os estagiários com relação ao que pode ocorrer na sala naquele momento: "passar esse conhecimento, essa prática, passar pra elas de repente uma situação que pode estar acontecendo alguma coisa, elas não imaginam o que pode vir depois, aí eu, como na minha prática eu já sei o que pode acontecer depois, aí eu já explicava antes..." (PC6).

Muitas vezes estas professoras se mostram preocupadas com seus alunos, como, por exemplo, quando o estagiário está passando determinado conteúdo e as mesmas percebem que alguma informação ficou falha. Neste momento elas complementam a matéria com aquilo que conhecem ou utilizam uma linguagem mais fácil para os alunos entenderem: "eu ajudei de alguma forma em questão de linguagem de quantidade de conteúdos, de planejar" (PC7).

Olh@ res, Guarulhos, v. 1, n1, p. 116-140, maio. 2013. 
Por outro lado, os professores da Educação Física adotam uma postura de nãoingerência sobre a postura dos estagiários, as habilidades desenvolvidas, o conteúdo ministrado ou o tipo de atividade. A concepção mais evidente destes professores para o conselho e supervisão do estágio é que na grande maioria das vezes eles acreditam que os estagiários necessitam errar para aprender e que a permanência na escola, a observação das ações dará ao futuro professor elementos para agir na prática pedagógica, mas apontam também para indicativos de mudanças: "Eu deixo correr um pouco pra ver o que vai dar. Pra ver se eles conseguem ou não solucionar os problemas, se vejo que continua a mesma dificuldade, dai eu interfiro" (PC 4); "eu comecei a ver o estágio de outra maneira e acho muito importante, criar oportunidade para estas pessoas e é uma oportunidade ótima para mim também, de estar atualizado e de ter uma ponte com a universidade” (PC2).

Já as professoras da Pedagogia tentam amenizar o choque com a realidade passando suas próprias experiências, prevendo as situações e alertando os estagiários: "a minha parte é facilitar a troca mesmo, de ele chegar aqui e eu estar aberta pra mostrar, pra ouvir, pra ver o que ele tem pra me dizer, acho que é mais por ai..." (PC9).

Os professores-colaboradores de ambos os lados se apoiam com mais propriedade na própria experiência para dar conselhos e fazer comentários: “eu tento colocar um pouco da minha experiência pra elas, não sou a dona da verdade não, nem sei se o que eu faço é o melhor dos trabalhos, mas alguma coisa eu tento passar" (PC11); "Fui aprendendo com o tempo" (PC3).

Observando os relatos dos participantes, pode-se perceber que a importância das ações dos professores-colaboradores está na experiência que possuem e que podem de alguma forma, demonstrá-las aos estagiários, ora deixando com que estes percebam seus próprios desafios ora auxiliando na maneira que agem com os alunos da escola. Neste sentido, Nóvoa (2008) coloca que a formação de professores deveria estar baseada na investigação, na importância das culturas colaborativas, do trabalho em equipe, do acompanhamento, da supervisão e da

Olh@ res, Guarulhos, v. 1, n1, p. 116-140, maio. 2013. 
avaliação dos professores. Se estas lógicas são construídas no âmbito da profissão, tanto na dimensão de fora para dentro como de dentro para fora, o processo de colaboração emerge naturalmente dentro do contexto da formação.

\section{Qual é o papel destes professores?}

Para conceber esta questão, existem duas possibilidades: a primeira é do ponto de vista das políticas públicas que vão mencionar que o professor-colaborador tem um papel único para o momento do estágio, pois ele possibilita o contato com o universo real de aprendizagem, mas por sua vez não dará suporte para o seu processo de formação, oferecendo "carta branca" para as universidades realizarem ou não algum curso neste sentido. O segundo ponto é a visão dos próprios professores-colaboradores sobre o seu papel no momento do estágio. Em ambos os cursos, eles se reconhecem como importantes na formação dos futuros professores, pois para os mesmos o estágio é um grande momento dentro do processo de tornar-se professor, mas eles não se veem como formadores.

No caso da Educação Física eles possuem uma visão tradicional de estágio como das antigas corporações de ofício onde o aprendiz se coloca ao lado do mestre para observar e repetir suas ações. Na Pedagogia as professoras tem na troca de experiências a principal concepção de estágio. Elas, ao relatarem sobre o que pensam e como concebem o estágio, em todos os depoimentos aparece a palavra "troca". Dessa forma, elas apontam que seu papel fica vinculado a passar um conhecimento prático aos estagiários, ao mesmo tempo em que recebem destes ideias novas, podendo ser teóricas ou não, como nos relatos dos participantes PC7 e PC8: “estágio eu acho que é um aprendizado duplo, [...] passar pra ela o pouco que eu sei, [...] e ao mesmo tempo ela aprender comigo também, ver como funciona a dinâmica, então eu acho que é um grande aprendizado, uma troca, bem legal” (PC7); "Informação, troca de experiências, estágio pra mim é tudo isso” (PC8).

Olh@ res, Guarulhos, v. 1, n1, p. 116-140, maio. 2013. 
Com um diferencial, a PC3 concebe seu papel como importante, mas coloca que depende da compreensão do estagiário:

Eu acho que tem estagiário que me deixa ser importante e outros não. É o comprometimento. Tem uns que não gostam de perguntar e que eu interfira. Meio naquela: ela é professora e eu sou estagiário e estou na universidade. Tem disso! Mas, tem aqueles que são bons. É conflito de relacionamento que acontece em qualquer lugar. Tem gente que é comprometido e gente que não está afim.

No entanto, por meio de seus relatos percebe-se que de maneira discreta esta situação começa a mudar gradualmente, pois os professores passam a reivindicar espaços para discussão, começam a pensar em novas dinâmicas para assessorar os estagiários, entre outros: "Os estagiários esperam um retorno. E como dar este retorno? (...) Mas uma estratégia é que me comprometo em conversar com os estagiários a final de cada encontro, pois talvez eu atenda as suas expectativas... antes não me dava conta que podia intervir” (PC2).

A partir dos apontamentos apresentados, é significativo aos docentes das escolas receberem uma formação e terem uma troca com os colegas da área, bem como com outros colegas. De modo que essa tarefa supõe que os pesquisadores universitários trabalhem nas escolas e nas salas de aula em colaboração com os professores para serem vistos não como sujeitos ou objetos de pesquisa, mas como colaboradores dos pesquisadores (TARDIF, 2000), isto é, como co-pesquisadores ou, melhor ainda, como co-elaboradores da pesquisa sobre seus próprios saberes profissionais (GAUTHIER et al., 1997; ZEICHNER \& CARO-BRUCE, 1999).

Porém, não se pode deixar de denunciar que a questão da formação dos professores-colaboradores é um caminho a ser percorrido, podendo de forma articulada realizá-la na universidade, mas sem políticas públicas que reconheçam a escola como lócus de formação, bem como de professores que exercem esta função, sem ser o coordenador pedagógico, não se vai muito longe.

Olh@ res, Guarulhos, v. 1, n1, p. 116-140, maio. 2013. 


\section{A relação com a Universidade}

Os professores-colaboradores concebem a relação com a UNESP-Rio Claro interessante porque eles se sentem apoiados por esta instituição e pelos cursos de formação que foram ministrados. Eles reconhecem que há um compromisso com a formação de professores. Sentem, ainda, a seriedade por parte dos supervisores e estagiários. Após os encontros de formação na Universidade, eles parecem entender melhor o contexto do estágio e suas necessidades, como no relato da PC3: "Acho que caminha bem. Me sinto assessorada. Já tive problema com estagiário de precisar ligar e vir resolver e daí veio e pronto. E mesmo assim eles aparecem, vem explicar, perguntam... me sinto amparada. É uma relação boa".

Os professores-colaboradores fazem elogios ao desempenho dos estagiários e reconhecem, neste momento, a importância da formação dos mesmos: " $E u$ acho que os alunos que tem vindo da UNESP eles tem uma visão mais ampla, tem alunos de outras universidades/faculdades que você vê (...) as estagiárias que estão aqui são excelentes, fiquei encantada com o trabalho delas” (PC1)

Especificamente no caso da Pedagogia, o curso de extensão trouxe ainda para alguns professores um retorno às leituras e estudos,

parece que reascende o gosto por leitura, por pesquisar, por se interessar mais, não achar que o que você está fazendo aqui na sala de aula está bom, não se acomodar eu acho que é a palavra. Eu acho que esse trabalho de a gente ter ido lá, do curso lá em si... reascendeu a pesquisa, o estudo (PC6).

bem como troca de experiências entre os participantes, não só com relação à prática de orientar os estagiários, mas às práticas da sala de aula também: “ $O$ curso lá é a parte que a Unesp está dando de retorno também. Então eu acho que está funcionando, está uma parceria legal”. (PC9)

cada estagiário tinha uma reação, cada estagiário tinha uma ideia, cada um tinha um comportamento e a hora que você achava que não sabia o que fazer, a outra sabia menos ainda sabe, eu achei super legal. E diferentes ideias de projetos pra trabalhar, muito bacana... (PC7).

Olh@ res, Guarulhos, v. 1, n1, p. 116-140, maio. 2013. 
De maneira geral, os professores-colaboradores envolvidos no curso se mostram satisfeitos com as medidas tomadas pela instituição. Esta perspectiva se torna real porque "nas atividades e profissões de interação humana como o magistério, o trabalhador está presente pessoalmente no local de trabalho" e sua pessoa constitui um "elemento fundamental na realização do processo de trabalho em interação com outras pessoas, isto é, com os alunos, os estudantes" (TARDIF, 2000, p.12). É o que se pode observar nos programas de formação e parceria envolvendo tanto a Pedagogia como a Educação Física. Eles não realizaram nada que outra universidade ou professor poderia realizar, pois a diferença estava na compreensão de que a colaboração é uma categoria a ser trabalhada, envolvendo o empenho mútuo dos participantes em um esforço coordenado para solucionar problemas. Não é uma relação hierárquica, onde as coisas são impostas; mas uma relação entre pessoas que saibam ouvir, compartilhar ideias e trabalhar juntas permitindo que haja uma constante interação entre os membros do grupo (MATURANA; VARELA, 2002; FIORENTINI, 2004; DILLENBOURG et al., 1996).

\section{Considerações finais}

A temática que nos propusemos a apresentar neste artigo engloba alguns dos diversos elementos que compõem o processo de estágio, o processo de formação. Dessa forma, o foco principal recaiu-se no professor-colaborador que recebe os estagiários da universidade, na tentativa de se elucidar sua importância para com o estágio e desvelar perspectivas de formação para a sua atuação.

Em nosso primeiro objetivo foi possível apresentar duas propostas de formação para professores-colaboradores advindos de dois cursos de graduação da UNESP- Rio Claro. Ambos se constituíram como projetos de extensão que atrelaram a necessidade de ser dar espaço e status ao estágio no processo de formação do futuro-professor, bem como dar vez e voz ao professor da escola

Olh@ res, Guarulhos, v. 1, n1, p. 116-140, maio. 2013. 
que atende aos estagiários. Embora com algumas lacunas e em desenvolvimento, essas iniciativas apresentam-se como uma possibilidade de articulação entre a universidade e a escola. A partir de relações mais próximas, pode ser possível visualizar parcerias e fortalecer a dimensão entre duas instâncias de formação, avançando-se para as discussões como a contribuição e o papel de cada um desses espaços.

Nesse ínterim caminha-se para o segundo objetivo de iniciar uma discussão sobre como o professor-colaborador se posiciona frente aos estágios e qual o sentido de uma formação para sua prática enquanto um possível "formador de professores".

Esse ponto é extremamente interessante, pois os professores-colaboradores são professores que acabaram agregando a noção de auxiliar no momento do estágio. Muitos se embasam nas suas experiências anteriores e acabam tendo como premissa transmitir elementos práticos para os estagiários. Contudo, após as vivências de formação, os mesmos passaram a conceber o estágio como um local imprescindível para formação. Devido às discussões, tanto do âmbito acadêmico como escolar, alguns pontos foram sendo evidenciados como, por exemplo, as ações adotadas, a necessidade da intervenção, a tomada de decisão frente as adversidades do estágio e a gestão da sala de aula e do estagiário. Foi possível perceber que os PC's, após receberem a formação, pareceram compreender melhor o universo do estágio supervisionado, começando a refletir sobre a importância do mesmo e sobre o próprio papel durante as aulas. Dessa forma, as contribuições da pesquisa se situam na compreensão alargada do processo de estágio com a discriminação dos papéis dos envolvidos e suas contribuições. Nesse sentido, exploramos o papel do professor-colaborador e todo o esforço de uma universidade em dar sentido ao seu processo de formação de professores. Contudo, ainda existem os limites/desafios, na tentativa de se aproximar da escola e que esta também se reconheça como crucial na formação de seus futuros profissionais. É importante que escola e

Olh@ res, Guarulhos, v. 1, n1, p. 116-140, maio. 2013. 
universidade tenham papéis definidos e garantidos no que diz respeito à formação dos professores, seja ela continuada ou inicial.

Fica em aberto as reflexões sobre a formação institucionalizada, sistematizada e formalizada do professor-colaborador, bem como o modo que esta instituição toma para si a responsabilização da formação de seus futuros professores, ocorrendo apenas em atitudes isoladas, partindo mais para o lado pessoal daqueles envolvidos, do que uma atitude profissional. Apontamentos esses, que poderão ser cristalizados em estudos futuros, uma vez que a temática estágio é uma referência na área de formação e tem potencialidade para ser melhor desenvolvida enquanto campo de investigação.

Agradecimentos: À Fundação de Amparo à Pesquisa do Estado de São PauloFAPESP.

Olh@ res, Guarulhos, v. 1, n1, p. 116-140, maio. 2013. 


\section{Referências Bibliográficas}

ALVES-MAZZOTTI, A. J.; GEWANDSZNADJDER, F. O método nas ciências naturais e sociais: pesquisa quantitativa e qualitativa. São Paulo: Pioneiras, 2002.

BARDIN, L. Análise de conteúdo. Lisboa: Edições 70, 1979.

BONDÍA, J. L. Notas sobre a experiência e o saber da experiência. Revista Brasileira de Educação, 19, Rio de Janeiro, p.20-28. 2002.

BORGES, C. A formação docente em Educação Física em Quebec: saberes espaços, culturas e agentes. In: TRAVERSIN, C., et al. (Orgs.) Trajetória e processos de ensinar e aprender: práticas e didáticas, livro 2 - XIV ENDIPE - Porto Alegre: EDIPUCRS, 2008.

BORGES, C. La collaboration enseignante en éducation physique et à la santé. In : PORTELANCE, L.; BORGES, C.; PHARAND, J. La collaboration dans le milieu de l’éducation. Québec: Presse de l'Université du Québec, pp.83-102., 2011.

BRASIL. Ministério da Educação. Decreto-Lei no. 1190, de 4 de abril de 1939.

. Ministério da Educação. Resolução n. ${ }^{\circ}$ 9, de 6 de outubro de 1969

. Ministério da Educação. Lei no 9394, de 20 de dezembro de 1996. Disponível em: <http://www.planalto.gov.br/ccivil_03/LEIS/19394.htm>. Acesso em: 23 out. 2006.

. Ministério da Educação. Parecer CNE/CP 28 de 2 de outubro de 2001.

- Ministério da Educação. Resolução CNE/CP 1, de 18 de fevereiro de 2002. Diário Oficial da União, Brasília, 4 de março de 2002. Seção 1, p. 8.

. Ministério da Educação. Lei no $\mathbf{1 1 . 7 8 8}$ de 25 de setembro de 2008.

CERRI, Y. L. N. S. O modelo de tutoria na formação de professores. In: Congresso de Iniciação Científica, 10, UNIMEP, Piracicaba, 2002.

CONTRERAS, J. A autonomia de professores. São Paulo: Cortez, 2002.

Olh@ res, Guarulhos, v. 1, n1, p. 116-140, maio. 2013. 
CORREA, B. C. Experiências de estágio em um curso de Pedagogia: vivências e desafios em busca de uma formação de qualidade. In: II Congresso Internacional CIDInE. Aveiro, Portugal. Anais. Novos contextos de formação, pesquisa e mediação.2009.

CYRINO, M.; BENITES, L.C.; SOUZA NETO, S. Programas de formação para professorescolaboradores da pedagogia e Educação Física da Unesp-Rio Claro. In: III Congreso Internacional sobre profesorado principiante e inserción profesional a la docencia. Anais..., 2012, Santiago, p. 1-9.

DEnZIN, N. K.; LINCOLN, Y. S. O Planejamento da Pesquisa Qualitativa: teorias e abordagens. Artmed: Porto Alegre, 2006.

GARCIA, C. M. A Formação de Professores: novas perspectivas baseadas na investigação sobre o pensamento do professor. In: Nóvoa, A. (Org.) Os professores e sua formação. Lisboa, D. Quixote, 1999, p.51-76.

GAUTHIER, C. et al. Por uma teoria da pedagogia: pesquisas contemporâneas sobre o saber docente. Ijuí: Unijuí, 1998

GERVAIS, C. A organização dos estágios e o acompanhamento do desenvolvimento profissional dos estagiários: a experiência quebequense. Impresso. No prelo. 2010.

GIGLIO, C. M. B. M. B. Residência pedagógica como diálogo permanente entre a formação inicial e continuada de professores. In: XV ENDIPE Convergências e tensões no campo da formação e do trabalho docente: políticas e práticas educacionais. Anais... Belo Horizonte. Coleção Didática e prática de Ensino: Autêntica, 2010, p. 375-394. 2010.

LUDKE, M.; ANDRÉ, M. E. D. A. Pesquisa em educação: abordagens qualitativas. São Paulo: EPU, 1986.

MATURANA, H. R.; VARELA, F. J. G. A árvore do conhecimento: as bases biológicas da compreensão humana. São Paulo: Palas Athenas, 2002.

MIZUKAMI, M. G. N., et al. Desenvolvimento profissional da docência: analisando experiências de ensino e aprendizagem. Pro-Posições. Campinas, 11(4), p.97-109, 2002.

NEIRA, M. G. Proposições para o estágio disciplinar na formaçao de professores de Educação Física. In: NASCIMENTO, J. V.; FARIAS, G. O. (Orgs.). Construção da identidade Olh@res, Guarulhos, v. 1, n1, p. 116-140, maio. 2013. 
profissional em educação física: da formação à intervenção. Florianópolis: Editora da UDESC, 2012, p.177-202.

NÓVOA, A. Formação de professores e profissão docente. In: Nóvoa, A. (Ed.) Os professores e sua formação. Lisboa: Dom Quixote, pp.15-34, 1992.

NÓVOA, A. The return of teachers. In: MINISTRY OF EDUCATION. Directorate-General for Human Resources in Education. Conference 'Teacher professional development for the quality and equity of lifelong learning'. Lisboa: European Commission, 2008, p.21-27.

ORTIZ, H. M. O professor reflexivo: (re) construindo o "ser" professor. IV Congresso de Educação do Movimento Humanidade Nova - Educação a fraternidade: um caminho possível? Vargem Grande Paulista, Movimento Humanidade Nova - Sala Temática: O professor reflexivo, p. 1-10 (texto mimeo), 2003.

PIMENTA, S. G.; LIMA, M. S. L. Estágio e Docência. São Paulo: Cortez, 2004.

PORTELANCE, L. et. al. La formation des enseignants associés et des superviseurs universitaires. Cadre de référence. Rapport de recherche, Table MELS-universités, 2008.

ROSA, M. I. P. et al. Contribuição à formação de professores de ciência: o modelo de tutoria. In: Atas Encontro Nacional de Pesquisa em Educação e Ciência. Bauru, 2003.

RUGIU, A. S. A nostalgia do mestre artesão. Campinas: Autores Associados, 1998.

SARTI, F. M. Parceria intergeracional e formação docente. Educação em revista. Belo Horizonte, 25 (2), pp. 133-152, 2009.

SHÖN, D. A. Formar professores como profissionais reflexivos. In: NÓVOA, A, (Coord.) Os professores e sua formação. Lisboa: Don Quixote, pp.77-91, 1992.

SOUZA NETO, S.; BENITES, L. C. Perspectivas para o desenvolvimento e construção do Ser-Professor: A Educação Física em questão. Projeto de extensão- PROEX. Unesp. Rio Claro, 2008.

SOUZA NETO, S. et al. O estágio supervisionado como prática profissional, área de conhecimento e locus de construção da identidade do professor de educação Física. In:

Olh@ res, Guarulhos, v. 1, n1, p. 116-140, maio. 2013. 
NASCIMENTO, J. V.; FARIAS, G. O. (Orgs.). Construção da identidade profissional em educação física: da formação à intervenção. Florianópolis: Editora da UDESC, 2012, p.113-140.

TARDIF, M. Saberes profissionais dos professores e conhecimentos universitários: elementos para uma epistemologia da prática profissional dos professores e suas conseqüências em relação à formação para o magistério. Revista Brasileira de Educação, Rio de Janeiro, Jan/Fev/Mar/Abr, p. $5-24,2000$

TARDIF, M. Saberes docentes e formação profissional. Petrópolis, RJ: Vozes, 2002.

TERRAZZAN, Eduardo Adolfo. Possibilidades para a formação inicial de professores de Física Estágio e Tutoria. In: V Escola de Verão para professores de Física, Química, Biologia e áreas afins. Bauru, 2000.

VIANNA, H. M. Pesquisa em Educação: a observação. Brasília: Líber Livro Editora, 2007.

VILLENEUVE, L. L'encadrement des stages supervisés. Montréal: Éditions Saint-Martin, 1994.

ZEICHNER, K. M.; CARO-BRUCE, C. The Madison Metropolitan School District classroom action-research program. Comunicação apresentada no quadro do simpósio Teacher research as professional development: three cases. Congresso anual da AERA. Montreal, abr.1999.

Olh@ res, Guarulhos, v. 1, n1, p. 116-140, maio. 2013. 